
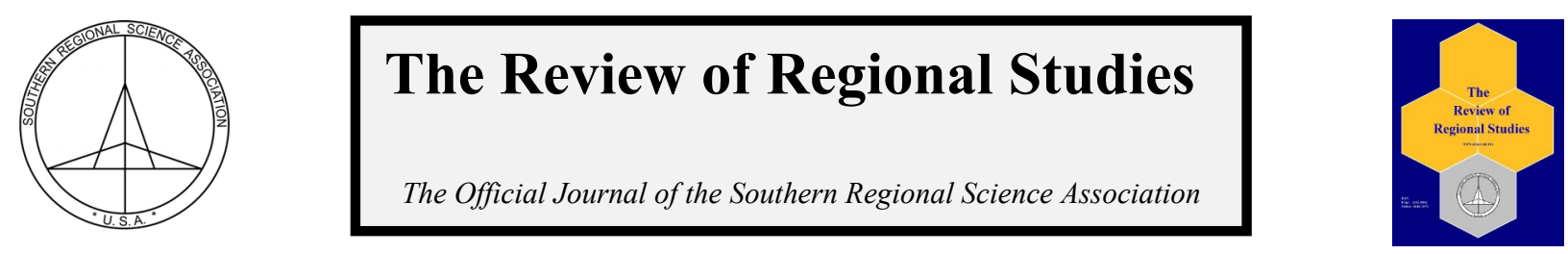

\title{
Accounting for Spatial Autocorrelation in the 2004 Presidential Popular Vote: A Reassessment of the Evidence
}

\author{
J. Wesley Burnett ${ }^{\mathrm{a}}$, Donald J. Lacombe \\ ${ }^{a}$ Division of Resource Management, West Virginia University, USA \\ ${ }^{b}$ Division of Economics, West Virginia University, USA
}

\begin{abstract}
Ordinary least squares econometric approaches to estimating election vote outcomes potentially ignore spatial dependence (or autocorrelation) in the data that may affect estimates of voting behavior. The presence of spatial autocorrelation in the data can yield biased or inconsistent point estimates when ordinary least squares is used inappropriately. Therefore, this paper puts forward a spatial econometric model to estimate the vote outcomes in the 2004 presidential election. We contribute to the literature in two ways. One, we extend the voting behavior literature by considering newly developed spatial specification tests to determine the proper econometric model. The results of two different spatial specification tests suggest that a spatial Durbin model provides a better fit to the data. Two, we offer a richer interpretation of the spatial effects, which differ from standard ordinary least squares estimates, of the county-level vote outcome for the 2004 presidential election.
\end{abstract}

Keywords: spatial econometrics, spatial Hausman test, 2004 presidential election

JEL Codes: C50, C21, $\mathrm{H} 10$

\section{INTRODUCTION}

The 2004 presidential election was a fractious campaign between two highly polarized political parties. The two main rivals were the Republican Party's candidate and incumbent President George W. Bush and the Democratic Party's candidate John Kerry, Senator from Massachusetts. More than 122 million Americans voted in the 2004 presidential election, with nearly 17 million more votes than in 2000 and until then the largest percentage increase in voter turnout since 1952 (Campbell, 2005). Of course we know the outcome now that Bush won the race with fifty-one percent of the popular vote, followed by Kerry with forty-eight percent, and Ralph Nader (Independent party candidate) with 0.38 percent (CNN, 2012). A county-level map of the 2004 presidential election results is offered in Figure 1-as in conventional representations, the red counties indicate the majority of the vote went to Bush whereas blue counties indicate the majority to Kerry. In total, Bush carried 31 states and accumulated enough electoral votes to propel him to a second term in office.

What explains the election's outcome? Why did the majority of American voters choose Bush over Kerry? Why was the election between the two so close? According to Campbell

\footnotetext{
Burnett is Assistant Professor, Division of Resource Management, 2044 Agricultural Sciences Building, PO Box 6108, West Virginia University, Morgantown, WV, 26506-6108. Lacombe is Associate Professor of Agricultural and Resource Economics and Economics, Research Associate Professor, Regional Research Institute, 886 Chestnut Ridge Road, PO Box 6825, Morgantown, WV 26506-6825. Corresponding Author: J.W. Burnett Email jwburnett@mail.wvu.edu
}

C) Southern Regional Science Association 2013. ISSN 1553-0892, 0048-749X (online) 


\section{Figure 1: 2004 County-level Presidential Election Results}

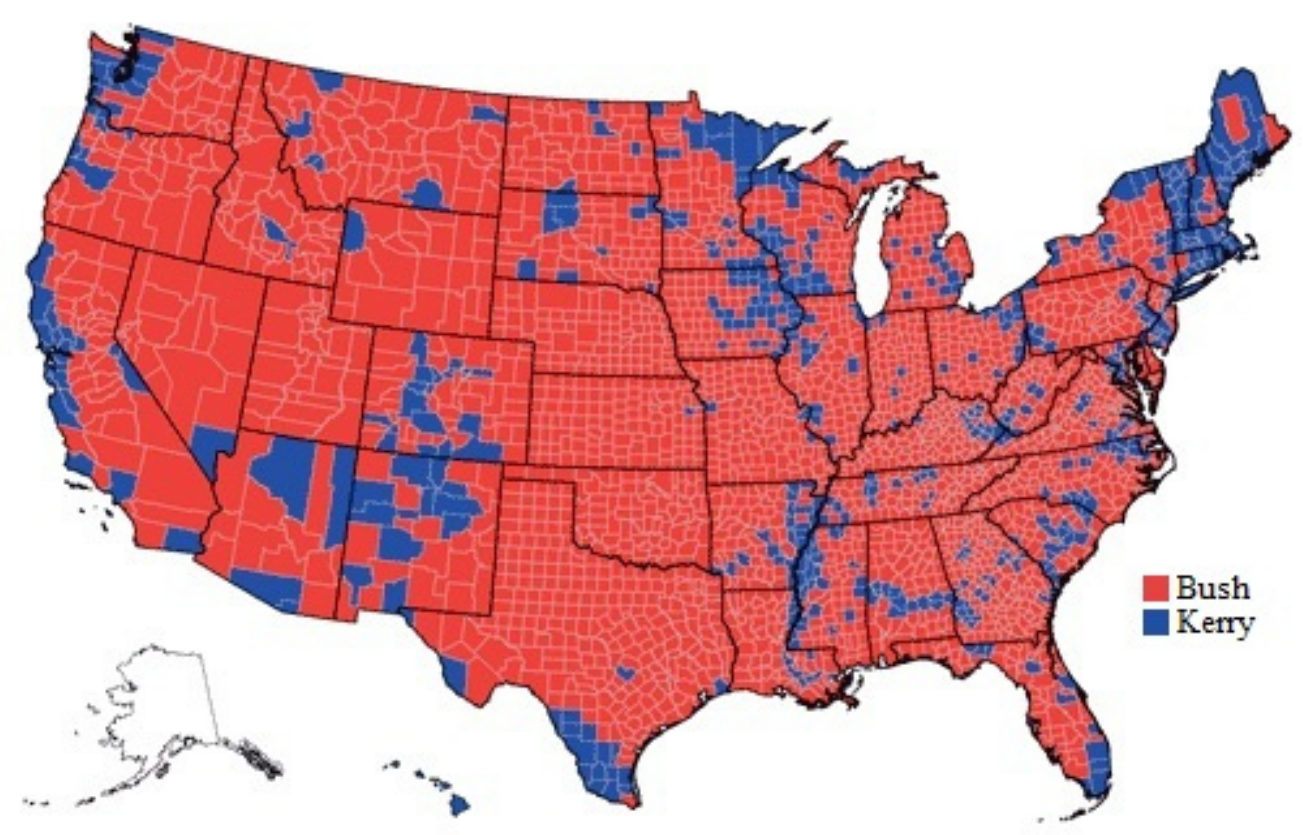

(2005), the answers essentially lie within the long-term influences on the vote and the developments of the campaign (i.e., the short-run influences).

From an econometric modeling standpoint it is somewhat simpler to estimate the shortrun influences, which may include indicators such as economic conditions, demographics, education level, party affiliation, religious affiliation, etc. (Blackley and Shepherd, 1994; Abrams and Butkiewicz, 1995; Fair, 1996; Alvarez and Nagler, 1998; Kan and Yang, 2001; Eisenberg and Ketcham, 2004). Long-run influences on voting behavior are more difficult to capture and generally necessitate some type of time series or panel data analysis to control for past influences on the current campaign. Although important for modeling dynamics in voting behavior, this paper abstracts from the long-term influences and instead focuses on the spatial influences in voting behavior.

As noted by several recent studies, spatial extensions of political econometric models are becoming increasingly popular (Beck et al., 2006; Franzese and Hays, 2007a,b; Darmofal, 2006). Space, in a geographic sense, may seem to be a concept too abstract for a political modeling context; however, Kim et al. (2003) found evidence for increasing geographical concentrations of partisan votes at the regional scale in the U.S. Specifically, the authors found that counties have become more likely to be clustered with similar counties in terms of their partisan support. The findings of Kim et al. (2003), were echoed in a series of reports by journalist Bishop (2004) who claimed, "Today, most Americans live in communities that are becoming more politically homogenous and, in effect diminishing dissenting views. And that grouping of like-minded people is feeding the nation's increasingly rancorous and partisan politics." In a similar line, Darmofal (2006) identifies that many theories in political science predict spatial clustering of similar behaviors among neighboring regions. He goes further to posit that spatial autocorrelation poses implications for both inference and modeling in political science, and emphasizes the importance of using proper diagnostic tools to determine the type of spatial 
autocorrelation within the data. Franzese and Hays (2007b) emphasize the importance of considering alternative specifications of spatial econometric models. In a separate study they find that unless the spatial autocorrelation is absent or minuscule, the spatial estimators "unambiguously" outperform nonspatial ordinary least squares (OLS) models often used in empirical work in political science (Franzese and Hays, 2007a). Lacombe and Shaughnessy (2007) point out that spatial models may help control for unobserved effects or influences in voting behavior that are difficult to quantify.

In line with these recent arguments in political science literature, we contribute to the literature by extending the spatial econometric approach of Lacombe and Shaughnessy (2007) to estimate the county-level vote outcomes of the 2004 presidential election. This study contributes to the voting behavior literature in two ways: (1) we apply newly developed spatial specification tests to determine the more appropriate models in context of the 2004 presidential election; and, (2) we offer an interpretation of the marginal effects within the county-level data based upon the appropriate specified model. In other words, we extend the literature by discussing new sets of specification tests within the spatial econometrics literature that can be used to test for the most appropriate (from a statistical standpoint) spatial econometric specification given the data. This study is not meant to consider the underlying theoretical issues within vote modeling but rather to offer a review of recent discussions and developments within the larger spatial econometrics literature. The literature review, therefore, will reflect these developments and abstract away from the voting model literature. This study is important because it can help researchers utilize proper diagnostics and algorithms to draw inferences from the most appropriate spatial econometric model. Finally, the study will offer an explanation of how to interpret marginal effects.

Looking ahead, our findings suggest that the spatial Durbin model is the most appropriate specification given the data. We then offer an interpretation of the correct marginal effects from our regression results.

This study is organized as follows. In the first section we will offer a review of recent discussions and developments in the spatial econometrics literature. This field of research is much too large to review in toto so we will limit the discussion to recent developments in spatial specification tests. The second section will be an amalgam of a literature review and methodological approach, which we define broadly as "Background." In the third section we discuss the data. In the fourth section, we explore: (1) the results of different spatial and nonspatial econometric models; (2) the results of the specification tests; and (3) an interpretation of the coefficients based upon the correct spatial econometrics model. In the final section we offer a discussion of the findings and explore future avenues of research.

\section{BACKGROUND}

The spatial econometrics literature has a relatively rich history with the first publication arguably beginning with the seminal work by Ord (1975). Several publications over the next decade would culminate in the first widely accepted textbook by Anselin (1988), a seminal work in its own right. Early research concentrated on cross-sectional, linear models but rapidly expanded to extensions to limited dependent variables, panel data, origin-destination flow models as well as others. As the amount of research in this field of econometrics expanded so did the empirical application across different disciplines including economics, political science, sociology, as well as a host of others. Today, one of the more popular texts, which contains a 
fairly comprehensive overview of spatial econometrics, is offered by LeSage and Pace (2009). LeSage and Pace (2009) provide a taxonomy of the different spatial econometric models we consider in this analysis. Specifically, we consider the spatial autoregressive model (SAR), the spatial error model (SEM), and the spatial Durbin model (SDM). For further specifics about these models we refer the reader to LeSage and Pace (2009).

\subsection{Spatial Specification Tests}

There are three types of classical, spatial specification test statistics: the Wald test, the Likelihood Ratio (LR) test, and the Lagrange Multiplier (LM) test (Burridge, 1980; Anselin, 1988; LeSage and Pace, 2009). Historically, the LM tests were used quite extensively because these tests only require OLS residuals. Burridge (1980) developed a LM test for the case of spatial dependence within the error terms. Anselin (1988) later developed a LM test for the spatial lag model. Both are distributed as chi-squared with one degree of freedom. One of the difficulties with the standard LM Lag and LM Error tests is that both ignore the possibility that the other form of spatial autocorrelation exists. In other words, the LM test for the spatial lag model assumes no spatial autocorrelation within the error term, and the LM test for spatial error correlation assumes no spatial autocorrelation in the dependent variable. To overcome this limitation, robust versions of these LM tests have been developed, namely the Robust LM Lag test and the Robust LM Error test. Past studies often selected the spatial model based upon the results of these tests by choosing the model with the highest test statistic value amongst the robust tests. Florax et al. (2003) contains additional information and insight on how these LM tests can be used in model selection.

Although the LM tests outlined here have been used frequently in model selection, additional tests have been developed to assist in this endeavor. For example, LeSage and Pace (2009) offered the insight that the coefficient estimates, $\beta$, in the OLS and SEM models should be the same, i.e. $\hat{\beta}_{O L S}=\hat{\beta}_{S E M}$. If the data are characterized by spatial dependence in the errors then OLS will yield unbiased coefficient estimates but biased standard error estimates. The authors then suggest a spatial Hausman test to test for equality in the OLS and SEM coefficients. The Hausman test is distributed chi-squared with $k$ degrees of freedom, where $k$ indicates the number of explanatory variables in the model. If the null hypothesis that $\hat{\beta}_{O L S}=\hat{\beta}_{S E M}$ is rejected then there may be a problem with omitted variable bias, which suggests a different spatial model specification. Given this insight, the authors advocate for the spatial Durbin model-a model they claim is far too underutilized in the literature (LeSage and Pace, 2009; Elhorst, 2010). Further, LeSage and Pace (2009) argue that the cost of ignoring spatial dependence with the dependent variable and/or with the independent variables (i.e., opting to rely on SEM results) is relatively high because it can result in omitted variable bias or inconsistency.

Based on the insights of LeSage and Pace (2009), Elhorst (2010) developed a diagnostic algorithm that used the SDM model as a point of departure and the various LM tests described earlier to determine the proper model. Assuming these tests reject the null of no spatial dependence, then he suggests using conventional likelihood ratio tests given the fact that the SAR and SEM models are nested within the SDM. The LR test basically determines if the SDM can be reduced to the SAR or SEM or neither-in which case the SDM is suggested. According to Elhorst (2010), the two null hypotheses for the LR test are

$$
H_{0}: \theta=0
$$

(C) Southern Regional Science Association 2013. 


$$
H_{0}: \theta+\rho \beta=0,
$$

where $\beta$ corresponds to the coefficients on the explanatory variables, $\theta$ corresponds to the coefficients on the spatially lagged explanatory variables, and $\rho$ corresponds to the coefficient on a spatially lagged dependent variable model. The first hypothesis determines if the SDM can be simplified to the SAR, whereas the second hypothesis determines if the SDM can be simplified to the SEM (Elhorst, 2010). If both hypotheses are rejected then the SDM arguably provides the best fit for the data.

\subsection{Interpreting Direct and Indirect Effects}

An additional extension of this paper offers a brief explanation for how to interpret the proper marginal effects once the results are obtained from a spatial econometric model. LeSage and Pace (2009) point out that using the point estimates, $\hat{\beta}_{r}$ (where $r$ refers to the $r^{\text {th }}$ explanatory variable) to determine the marginal effects will lead to erroneous conclusions. Instead, the authors suggest a procedure for calculating what they define as direct and indirect effects. An interpretation of these effects is that a change in a single observation (county) associated with any given explanatory variable will affect the county itself (direct effect) and potentially affect all the other counties indirectly (an indirect effect) (LeSage and Pace, 2009). The scalar summary measures of indirect effects represent the cumulative spillovers. The sum of these impacts is defined as the total effect. These effects estimates differ from the point estimates because there are feedback and spillover effects that arise as a result of impacts passing through neighboring counties and then back through the counties themselves (LeSage and Pace, 2009). Therefore, we will report these effects estimates to offer a richer interpretation of the marginal effects within the model. A more rigorous analysis of the estimation and interpretation of direct and indirect effects is offered in LeSage and Pace (2009).

\section{DATA}

The data for this study are identical to the original work that explored county-level voting outcomes for the 2004 election (Lacombe and Shaughnessy, 2007); however, we alter the original data set by eliminating the variables for percentage of religious adherents, churches per 10,000 people, and the dummy variables for Massachusetts and Texas. Instead of the original religious variables we include a variable for the percentage of evangelical Protestants at the county level - a further discussion of this variable is included below. In addition to the data augmentation, we also extend the original work to consider the correct spatial model specification and interpretation of the spatial effects. Definitions, summary statistics, and sources are presented in Table 1. All variables are measured at the county level.

The dataset contains various demographic indicators including the county-level percentage of African Americans, Caucasians, people of Hispanic ethnicity, female population with at least a bachelor's degree, male population with at least a bachelor's degree, and the percentage of the population that are veterans. Demographic indicators were obtained from the 2000 Census (Census Bureau, 2000) with specific summary files (SF) indicated in Table 1.

An additional demographic variable includes the percentage of the county-level population living in what the Census Bureau designates as an urban area; i.e., densely developed residential, commercial, and other nonresidential areas (Census Bureau, 2000). Historically, 
Table 1: Data definitions and summary statistics

\begin{tabular}{|c|c|c|}
\hline Definitions & Mean & $\begin{array}{l}\text { Standard } \\
\text { Deviations }\end{array}$ \\
\hline$\%$ vote for Bush & 0.6048 & 0.1247 \\
\hline$\%$ Black & 8.630 & 14.37 \\
\hline$\%$ White & 84.96 & 15.97 \\
\hline$\%$ Hispanic & 6.208 & 12.10 \\
\hline$\%$ Urban population & 0.3938 & 0.3035 \\
\hline Female population w/ bachelors & 0.1092 & 0.0483 \\
\hline Male population w/ bachelors & 0.1089 & 0.0510 \\
\hline Gay marriage dummy & 0.2802 & 0.4492 \\
\hline$\%$ Veterans & 0.1396 & 0.0291 \\
\hline$\%$ Protestant evangelicals & 0.2331 & 0.1621 \\
\hline Log per capita personal income & 9.741 & 0.2716 \\
\hline Unemployment rate & 5.663 & 1.799 \\
\hline
\end{tabular}

urban voters have favored Democratic candidates (McKee and Shaw, 2003; Sauerzopf and Swanstrom, 1999), so we hypothesize a negative relationship between percentage of urban population and vote outcome in favor of Bush in the 2004 election.

The variable Gay marriage is a dummy variable to indicate that a particular state had an amendment to ban same-sex marriage on the 2004 presidential ballot. Same-sex marriage was a highly controversial issue for the 2004 election in which 13 states offered constitutional amendments to ban the practice. Exit polls showed a large number of voters who identified "moral values" as the most important determinant of their vote, and therefore, many analysts have emphasized the role of religious right and beliefs in same-sex marriage in motivating Bush's base to get out and vote (Lewis, 2005). Thus, we predict a positive relationship between this state-level indicator and the county-level vote outcome in favor of Bush.

Based upon the analysis of Lewis (2005), which indicated that Bush's voting base was motivated by the religious right and the belief in same-sex marriage, we define an additional variable for the percentage of evangelical Protestants at the county level. These two variables were obtained from the Association of Religion Data Archives (ARDA, 2010), which counted congregational groupings and membership at the county level in 2010 . Hence, we predict a positive relationship between this variable and the county-level vote outcome in favor of Bush.

Finally, we used two economic indicators: county-level per capita personal income (Bureau of Economic Analysis, 2004) and the county-level unemployment rate (Bureau of Labor Statistics, 2004). According to Blackley and Shepherd (1994), presidential elections often constitute a national referendum on economic policy. This can be especially true for incumbent presidents who reside in office during times of persistently poor economic conditions. Those who blame the president for such conditions may offer a vote of no confidence in the incumbent by voting in favor of the opposing candidate. Such conditions are partially to blame for George H.W. Bush's defeat in the 1992 presidential election (Wines, 1992). Therefore, we predict that the county-level unemployment rate is negatively related to a vote outcome in favor of Bush.

Our dataset differs from Lacombe and Shaughnessy (2007) by omitting the dummy variables for Texas and Massachusetts, which in the original study were meant to capture voting 
biases towards Bush (Kerry) since his home state is Texas (Massachusetts). These variables were omitted because any significant findings may be due to a large Republican voting base in Texas and Democratic voting base in Massachusetts. ${ }^{1}$

\section{RESULTS}

We begin this section by estimating the model using OLS and all the spatial specifications outlined in the Background section of this paper. We then compare our results to that of Lacombe and Shaughnessy (2007). In the current analysis, we specify a first-order contiguity spatial weighting matrix, in which counties that share a common border are considered neighbors. ${ }^{2}$ The weighting matrix is row-normalized so that the spatial autocorrelation coefficient can be interpreted as the average effect of neighboring county observations on local vote outcomes. Following the estimation results we explore the specification tests outlined earlier.

Consistent with Lacombe and Shaughnessy (2007), our baseline is the OLS model which is specified as

$$
\begin{aligned}
\% \text { Bush }= & \text { constant }+\beta_{1} \text { black }+\beta_{2} \text { white }+\beta_{3} \text { hispanic }+\beta_{4} \text { urban } \\
& +\beta_{5} \text { female }+\beta_{6} \text { male }+\beta_{7} \text { gay }+\beta_{8} \text { veterans }+\beta_{9} \text { protestants } \\
& +\beta_{10} \text { income }+\beta_{11} \text { unemp }+\varepsilon .
\end{aligned}
$$

We experimented with different specifications of the above model and found that this specification provided the best fit of the data, and we found stable coefficient estimates across the different specifications implying no significant bias.

The original findings of Lacombe and Shaughnessy (2007) are presented in Table 2. Comparing our findings (Table 3 ) to the original work, we find remarkably similar results to the original OLS results in terms of signs, magnitudes, and statistical significance. The main difference is that we find a statistically significant, positive effect of the percentage of evangelical Protestants (at the county level) on the vote outcome for Bush-this differs as the original variable "adherents" was insignificant. Lacombe and Shaughnessy (2007) defined a variable for religious "adherents" which was measured as a person belonging to one of 149 religious groups. The current variable of evangelical Protestant is much narrower and is expected to yield more accurate results as evangelic Protestants played a prominent role in the vote for Bush (Jones, 2004). For the SEM model, we find remarkably similar results in terms of signs, magnitudes, and statistical significance. Once again, the main difference falls within the variable of evangelical Protestants - the SEM results for the current study yields a statistically insignificant result for the protestant variable whereas the original work found a highly significant, positive effect of "adherents."

The OLS regression results for the current study are listed in column two of Table 3 . These estimates suggest a ten percentage point increase in white voters would lead to a 0.019 unit increase in the percentage of vote outcome in favor of Bush - a small but highly significant

\footnotetext{
${ }^{1}$ We thank an anonymous referee for this insight.

2 The contiguity matrix was estimated by computing the Voroni diagrams and Delaunay triangles. The program for this computation was obtained from the Matlab package developed by LeSage (2010).
}

(C) Southern Regional Science Association 2013. 
Table 2: Original Results of Lacombe and Shaughnessy (2007)

\begin{tabular}{|c|c|c|}
\hline Variable & OLS & SEM \\
\hline \multirow[t]{2}{*}{ Constant } & $1.4827 * * *$ & $0.5823 * * *$ \\
\hline & -8.86 & -5.27 \\
\hline \multirow[t]{2}{*}{ 'Black } & -0.0006 & $-0.0022 * * *$ \\
\hline & $(-1.47)$ & $(-8.92)$ \\
\hline \multirow[t]{2}{*}{ White } & $0.0016^{* * *}$ & $0.0037 * * *$ \\
\hline & $(4.30)$ & (18.64) \\
\hline \multirow[t]{2}{*}{ Hispanic } & -0.0002 & -0.0002 \\
\hline & $(-0.57)$ & $(-0.95)$ \\
\hline \multirow[t]{2}{*}{ Urban Pop } & -0.0025 & -0.0073 \\
\hline & $(-0.26)$ & $(-1.26)$ \\
\hline \multirow[t]{2}{*}{ Female BA } & $-1.1312 * * *$ & $-0.4436^{* * *}$ \\
\hline & $(-10.13)$ & $(-6.26)$ \\
\hline \multirow[t]{2}{*}{ Male BA } & $0.8016^{* * *}$ & $0.1262 *$ \\
\hline & (7.09) & $(1.88)$ \\
\hline \multirow[t]{2}{*}{ Gay } & $0.0221 * * *$ & 0.0102 \\
\hline & $(5.61)$ & $(1.59)$ \\
\hline \multirow[t]{2}{*}{ Veteran } & $0.2432 * * *$ & $0.2056^{* * *}$ \\
\hline & $(3.42)$ & $(3.82)$ \\
\hline \multirow[t]{2}{*}{ Adherents } & 0.015 & $0.0267 * * *$ \\
\hline & $(1.07)$ & $(2.71)$ \\
\hline \multirow[t]{2}{*}{ Churches } & $0.0017 * * *$ & 0.0003 \\
\hline & $(7.06)$ & $(1.56)$ \\
\hline \multirow[t]{2}{*}{ Texas } & $0.1171 * * *$ & $0.0610^{* * *}$ \\
\hline & $(15.22)$ & $(3.79)$ \\
\hline \multirow[t]{2}{*}{ Massachusetts } & $-0.1690^{* * *}$ & $-0.0564^{* *}$ \\
\hline & $(-8.23)$ & $(-2.20)$ \\
\hline \multirow[t]{2}{*}{ Per Cap Inc } & $-0.0901 * * *$ & $-0.0235^{* *}$ \\
\hline & $(-5.34)$ & $(-2.10)$ \\
\hline \multirow[t]{2}{*}{ Unemployment } & $-0.0262 * * *$ & $-0.0096^{* * *}$ \\
\hline & $(-18.13)$ & $(-9.11)$ \\
\hline \multirow[t]{2}{*}{$\lambda$} & - & $0.8810^{* * *}$ \\
\hline & - & $(84.29)$ \\
\hline Adjusted $R^{2}$ & 0.4150 & 0.7775 \\
\hline
\end{tabular}

Notes: $* * *, * *$, and $*$ denote a statistical significance level of one, five, and ten percent, respectively. $t$-statistics are presented in parentheses below the coefficient estimates.

effect. These results also suggest that as the percentage of females with a bachelor's degree in a county increase by one, then there is a 1.09 percentage point decrease in the votes for Bush. Conversely, if a male has a bachelor's then there is a marginal effect of a 0.77 percentage point increase in the votes for Bush. Following the same logic, we find positive (statistically significant) marginal effects on the percentage of Bush votes with veterans and Protestants. These outcomes are consistent with expectations as Bush appealed to veterans and religious voters in the 2004 election. The county-level unemployment rate is negatively related to the vote 
Table 3: Nonspatial and Spatial Regression Results

\begin{tabular}{|c|c|c|c|c|}
\hline Variable & OLS & "SAR & "SEM & 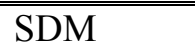 \\
\hline Constant & $\begin{array}{l}1.7669 * * * \\
(12.4539)\end{array}$ & $\begin{array}{l}0.3011 * * * \\
(2.9487)\end{array}$ & $\begin{array}{l}0.5400 * * * \\
(4.7671)\end{array}$ & $\begin{array}{l}0.7552 * * * \\
(391.3417)\end{array}$ \\
\hline Black & $\begin{array}{l}-0.0005 \\
(-1.5873)\end{array}$ & $\begin{array}{l}0.0008 * * * \\
(3.7060)\end{array}$ & $\begin{array}{l}-0.0022 * * * \\
(-8.6465)\end{array}$ & $\begin{array}{l}-0.0024 \\
(-0.0049)\end{array}$ \\
\hline White & $\begin{array}{l}0.0019 * * * \\
(7.2549)\end{array}$ & $\begin{array}{l}0.0023 * * * \\
(12.1965)\end{array}$ & $\begin{array}{l}0.0039 * * * \\
(19.7152)\end{array}$ & $\begin{array}{l}0.0039 * * * \\
(3.8353)\end{array}$ \\
\hline Hispanic & $\begin{array}{l}0.0014 * * * \\
(7.0351)\end{array}$ & $\begin{array}{l}0.0011 * * * \\
(7.4755)\end{array}$ & $\begin{array}{l}0.0001 \\
(0.3075)\end{array}$ & $\begin{array}{l}0.0000 \\
(0.0311)\end{array}$ \\
\hline Urban Pop & $\begin{array}{l}-0.0547 * * * \\
(-6.9861)\end{array}$ & $\begin{array}{l}-0.0396 * * * \\
(-7.0330)\end{array}$ & $\begin{array}{l}-0.01268 * * \\
(-2.5590)\end{array}$ & $\begin{array}{l}-0.0111 * * * \\
(-6.4095)\end{array}$ \\
\hline Female BA & $\begin{array}{l}-1.0848 * * * \\
(-10.0653)\end{array}$ & $\begin{array}{l}-0.6317 * * * \\
(-8.1525)\end{array}$ & $\begin{array}{l}-0.4484 * * * \\
(-6.2996)\end{array}$ & $\begin{array}{l}-4.4840 * * * \\
(-6.6257)\end{array}$ \\
\hline Male BA & $\begin{array}{l}0.7744 * * * \\
(7.1424)\end{array}$ & $\begin{array}{l}0.4249 * * * \\
(5.4515)\end{array}$ & $\begin{array}{l}0.1316^{*} \\
(1.9440)\end{array}$ & $\begin{array}{l}0.1680 \\
(1.2803)\end{array}$ \\
\hline Gay & $\begin{array}{l}0.0156 * * * \\
(3.5752)\end{array}$ & $\begin{array}{l}0.0107 * * * \\
(3.4145)\end{array}$ & $\begin{array}{l}0.0083 \\
(1.3015)\end{array}$ & $\begin{array}{l}0.0063 \\
(0.0803)\end{array}$ \\
\hline Veteran & $\begin{array}{l}0.2137 * * * \\
(3.1246)\end{array}$ & $\begin{array}{l}0.2374 * * * \\
(4.8264)\end{array}$ & $\begin{array}{l}0.2068^{* * *} \\
(3.7832)\end{array}$ & $\begin{array}{l}0.1913 \text { *** } \\
(6.7352)\end{array}$ \\
\hline Protestants & $\begin{array}{l}0.0646 * * * \\
(5.2422)\end{array}$ & $\begin{array}{l}0.02281 * * \\
(2.5758)\end{array}$ & $\begin{array}{l}-0.0101 \\
(-1.1981)\end{array}$ & $\begin{array}{l}-0.0144 * * * \\
(-11.5003)\end{array}$ \\
\hline Per Cap Inc & $\begin{array}{l}-0.1141 * * * \\
(-8.0809)\end{array}$ & $\begin{array}{l}-0.0243 * * \\
(-2.3867)\end{array}$ & $\begin{array}{l}-0.0184 \\
(-1.6078)\end{array}$ & $\begin{array}{l}-0.0218 \\
(-0.3487)\end{array}$ \\
\hline Unemployment & $\begin{array}{l}-0.0287 * * * \\
(-22.7445)\end{array}$ & $\begin{array}{l}-0.0132 * * * \\
(-14.5833)\end{array}$ & $\begin{array}{l}-0.0092 * * * \\
(-8.7036)\end{array}$ & $\begin{array}{l}-0.0089 \\
(-0.8091)\end{array}$ \\
\hline$\rho$ & $\begin{array}{l}- \\
-\end{array}$ & $\begin{array}{l}0.6999 \\
(356.7509)\end{array}$ & - & $\begin{array}{l}0.8180 * * * \\
(6.3279)\end{array}$ \\
\hline$\lambda$ & $\begin{array}{l}- \\
-\end{array}$ & $\begin{array}{l}- \\
-\end{array}$ & $\begin{array}{l}0.8840 * * * \\
(89.8544)\end{array}$ & $\begin{array}{l}- \\
-\end{array}$ \\
\hline Adjusted $R^{2}$ & 0.3419 & 0.1639 & 0.7757 & 0.4802 \\
\hline
\end{tabular}

Notes: '***', '**', and '*' denote a statistical significance level of one, five, and ten percent, respectively.t-statistics are presented in parentheses below the coefficient estimates. The coefficients on the spatially lagged dependent variables have been omitted from the SDM model.

outcome for Bush; this too is consistent with expectations as presidential election campaigns are often economic policy referendums for incumbent presidents (Blackley and Shepherd, 1994).

Before considering the estimation results of the spatial models, we first consider the results of the various specification tests presented in Table 4 . We begin by conducting the classical LM tests (along with their robust counterparts) to determine if the SAR or SEM model is a more appropriate specification. As can be gleaned from the results, both tests (and robust counterparts) yield highly significant results. Both of these test statistics suggest that a spatial error model (SEM) is preferred over the nonspatial OLS. Lacombe and Shaughnessy (2007) found similar results with the LM tests and proceeded by following the recommendation of Florax et al. (2003) to select the model specification with the highest value of the robust LM test statistics-in this case the SEM model. Therefore, they followed the proper procedure as the LM tests were the only tools at their disposal; however, recalling the insight from LeSage and Pace (2008, 2009), the coefficient estimates for the OLS and SEM models theoretically should be the 
Table 4: Spatial Specification Tests

\begin{tabular}{|c|c|}
\hline Diagnostic Test & Results \\
\hline \multicolumn{2}{|l|}{ Classical LM Tests } \\
\hline LM Lag & $2247.2157 * * *$ \\
\hline$\chi^{2}(1): 0.01$ Value & $(17.6110)$ \\
\hline LM Error & $2840.5194 * * *$ \\
\hline$\chi^{2}(1): 0.01$ Value & $(6.6400)$ \\
\hline \multicolumn{2}{|l|}{ Robust LM Tests } \\
\hline LM Lag & $14.4358^{* * *}$ \\
\hline$\chi^{2}(1): 0.01$ Value & $(6.6400)$ \\
\hline LM Error & $610.1728^{* * *}$ \\
\hline$\chi^{2}(1): 0.01$ Value & $(6.6400)$ \\
\hline Spatial Hausman Test & $96.4374 * * *$ \\
\hline & \\
\hline \multicolumn{2}{|l|}{ Elhorst Testing Procedure } \\
\hline LR test $\left(H_{0}: \theta=0\right)$ & $1116^{* * *}$ \\
\hline$\chi^{2}(k): 0.01$ Value & $(26.2170)$ \\
\hline LR test $\left(H_{0}: \theta+\rho \beta=0\right)$ & $158.5059^{* * *}$ \\
\hline$\chi^{2}(k): 0.01$ Value & $(26.2170)$ \\
\hline
\end{tabular}

same. We extend the previous study by testing for the equality of coefficients between the two models using a spatial Hausman test. The results for this test are presented in Table 4. The null hypothesis for this test is that the difference between the $\hat{\beta}$ coefficient estimates (for each model) are not statistically different from zero. Our results for the spatial Hausman suggest the contrary; i.e., the estimated difference between the coefficients of these two models are indeed (highly) statistically different from zero. In such a case, LeSage and Pace (2009) recommend the spatial Durbin model as there is a potential problem of omitted variable bias in the SEM model.

The model comparison algorithm offered by Elhorst (2010) allows us to then extend the analysis once again by further testing the SDM model using likelihood ratio tests. The two null hypotheses in (1) and (2) are rejected, corroborating the results of the spatial Hausman test, suggesting that the spatial Durbin model provides the best fit given the data under purview.

Since the diagnostic tests suggest the spatial Durbin model as the most appropriate specification, we focus on the interpretation of the effects estimates offered by the SDM regression results. Referring to Table 3, the estimated spatial autocorrelation coefficient on the lagged dependent variable, $\rho$, for the spatial Durbin model suggests positive and highly significant spatial dependence within the percentage of vote outcomes for Bush at the county level. This result suggests spatial dependence within the data, but to properly interpret the marginal effects we must examine the direct, indirect, and total effects. 
Each of the effects (direct, indirect, and total) may be of interest for analysis for various reasons. Recall that the direct effect estimates the marginal effect of a change in an explanatory variable in a county on the dependent variable in that same county, whereas the indirect effect estimates the marginal effect of a change in an explanatory variable in a county on the dependent variable in neighboring county-level observations. That is, the scalar summary, indirect estimates report cumulate spillovers falling on all neighboring counties, neighbors to these neighboring counties, and so on, then averages these overall sample observations. The total effect is simply the sum of these two combined effects. A political analyst would not be able to draw inferences for their individual county, since the scalar summary measure of direct effects reported represents an average over all counties in the sample. However, an analyst might be interested in which variables exert spillover effects. Knowledge of these spillover effects estimates can provide a much richer set of results relative to a standard aspatial nonspatial OLS model.

The effects estimates, based upon the spatial Durbin model results, are presented in Table 5. An interpretation on the percentage of black voters within a county population (Black) is that an increase in this percentage has a negative, marginal direct, indirect, and total effect on local vote outcomes for Bush but each of these effects is insignificant for this variable. The effects of the percentage of white voters within a county yield the interesting result of a positive

Table 5: Spatial Durbin Model Direct and Indirect Effects Estimates

\begin{tabular}{lrrr}
\hline \hline Variable & \multicolumn{1}{c}{ Direct } & \multicolumn{1}{c}{ Indirect } & \multicolumn{1}{c}{ Total } \\
\hline \hline Black & -0.0756 & -6.0281 & -6.1040 \\
White & $(-0.1074)$ & $(-0.3795)$ & $(-0.3706)$ \\
Hispanic & $0.0036^{* * *}$ & -0.0028 & 0.0008 \\
& $(2.8978)$ & $(-0.2375)$ & $(0.0642)$ \\
Urban Pop & 0.0001 & 0.0079 & 0.0081 \\
& $(0.3373)$ & $(0.3462)$ & $(0.3522)$ \\
Female BA & $-0.0162^{* * *}$ & -0.1956 & -0.2118 \\
& $(-2.6781)$ & $(-0.6012)$ & $(-0.6400)$ \\
Male BA & $-0.6688^{* * *}$ & -7.2873 & -7.9561 \\
& $(-2.7887)$ & $(-0.5873)$ & $(-0.6300)$ \\
Gay & 0.3737 & 8.9012 & 9.2755 \\
Veteran & $(1.069)$ & $(0.5245)$ & $(0.5365)$ \\
Protestants & -0.0321 & -2.5626 & -2.5946 \\
& $(-0.1967)$ & $(-0.3596)$ & $(-0.3571)$ \\
Per Capita Inc & $0.1395 * * *$ & -1.7361 & -1.5966 \\
Unemployment & $(9.4290)$ & $(-0.6996)$ & $(-0.6413)$ \\
& $(-11.2613)$ & $(0.4600)$ & $(0.2549)$ \\
\hline \hline N & -0.0290 & 0.0514 & 0.02234 \\
& $(-0.4698)$ & $(0.0321)$ & $(0.0138)$ \\
& $(-0.0051$ & 0.3311 & 0.3260 \\
& $(0.2194)$ & $(0.3175)$ & $(0.3066)$ \\
\hline
\end{tabular}

Notes: $* * *, * *$, and $*$ denote a statistical significance level of one, five, and ten percent, respectively. t-stats are presented in parentheses below the coefficient estimates.

(C) Southern Regional Science Association 2013. 
direct effect on the percentage of positive vote outcomes for Bush, but a negative indirect effect (although the indirect estimate is insignificant). ${ }^{3}$ A statistically significant indirect effect estimate (which captures cumulative spillovers) would help substantiate the results of Kim et al. (2003) who found that counties have become more likely to be clustered with similar counties in terms of their partisan support-unfortunately, we find no such significance. The estimate for the percentage of female voters with a bachelor's degree, suggest a highly significant, negative effect on the vote outcome for Bush at the county level. These estimates are corroborated by CNN (2012) which reported that a majority of women (any educational status) favored Kerry over Bush with the former garnering 51 percent of the vote over the latter with 48 percent of the vote. The coefficient estimates of percentage of males with a bachelor's suggest the opposite, but all the effects are statistically insignificant. Consistent with expectations, the results suggest positive, direct effects on Bush votes by veteran voters. Interestingly, the coefficient estimate on evangelical Protestants at the county level indicates a negative and highly significant direct effect on the vote outcome for Bush. This result is inconsistent with expectations as a majority of Protestants voted in favor of Bush in the 2004 election (CNN, 2012). The unemployment rate estimate indicates a negative direct effect on vote outcomes for Bush. This is consistent with aforementioned expectations that presidential elections often serve as referenda on economic policy for incumbent presidents (Blackley and Shepherd 1994). But, this variable also is statistically insignificant. A final empirical result is worth mentioning. Lacombe and Shaughnessy (2007) found that the dummy variable gay, which represents states that had a gay marriage ballot initiative, was insignificant. We find in our SDM model that the effects estimates for this variable are all insignificant, lending credence to the hypothesis that this was not necessarily a motivating factor in the election.

\section{DISCUSSION}

In this study we extended a previous analysis by Lacombe and Shaughnessy (2007) to offer a rigorous set of specification tests to determine the most appropriate spatial model specification in context of the 2004 presidential election. This study extended the previous one because such diagnostic tools were not available at the time of the original publication. Given these new specification tests, our analysis points to a different type of spatial econometric model-the spatial Durbin model. The results of the new model suggest different results because of the spatial autocorrelation within the dependent variable (vote outcome for Bush at the county level). The insights of LeSage and Pace (2009) show it is erroneous to compare the point estimates between two spatial models, so we do not compare our estimate results to the earlier study, but we do find a statistically significant, spatial autocorrelation coefficient. Additionally, we were able to calculate the proper marginal effects, i.e. the direct, indirect, and total effects for the explanatory variables. Among these marginal effects, the indirect cumulative effect allowed us to appeal to arguments of spatial spillovers within the county-level data, something that Lacombe and Shaughnessy (2007) were not able to do because they were arguably using the wrong model to draw inferences.

Although we did not find statistically significant indirect effects to indicate cumulative spillovers in voting behavior, we did find highly significant spatial autocorrelation coefficients across all of our spatial econometric models. Further, our spatial diagnostic test results imply

\footnotetext{
${ }^{3}$ Note that the total effect is a cumulative measure of the direct and indirect effects. The marginal, positive direct effect outweighs the marginal, negative indirect effect so the total effect is positive, although again the total effect is insignificant.
}

(C) Southern Regional Science Association 2013. 
strong evidence of spatial autocorrelation both within the dependent variable (percentage vote for Bush at the county level) and among the explanatory variables. These findings confirm that of Kim et al. (2003) who found increasing geographical clustering or concentration of partisan votes, and more specifically, that counties have a tendency to be clustered with similar counties in terms of their partisan support. If such a geographical political polarization is taking place in the U.S. then incorporating spatial econometric techniques may yield more accurate estimates of voting behavior.

As noted by Darmofal (2006) and Franzese and Hays (2007a,b), spatial econometric models are becoming increasing popular in the applied political science literature. As these applications continue to grow, it is important to rigorously consider the correct spatial econometric model specification. This study can serve as an initial roadmap for future researchers interested in voting outcomes. Specification is important because the utilization of the incorrect spatial model may yield biased parameter estimates as well as incorrect interpretation of the marginal effects. It is important to offer a correct interpretation of the marginal effects because the interpretation of the coefficient estimates as one would do in the OLS context is no longer appropriate.

In the political science literature, the estimation and interpretation of the effects estimates can have numerous applications. For example, in this study we examined the effects estimates to interpret how certain determinants of presidential vote outcomes affect the vote locally and spillover into surrounding neighbors. Outside of legislative or electoral arena, Franzese and Hays (2007a) use spatial models to analyze European governments' labor market expenditures. Other examples may include the interdependence of states' actions in international relations; states' entry into war, alliances, treaties; contextual effects on voting behavior, etc. (Franzese and Hays, 2007b). Spatial econometric models, when appropriately utilized, can offer additional insights into various political economy questions that are not available in standard econometric models.

This study suffers from potential issues of ecological inference (Shively, 1969); i.e., problems of inferring individual-level behavior from aggregate (county level) data. Although, as Kim et al. (2003) point out, the problem of ecological fallacy is far less severe with county-level data as opposed to state-level data, and county-level data are the smallest spatial unit of analysis that allows for the inclusion of macroeconomic variables such as the unemployment rate.

\section{REFERENCES}

Abrams, Burton A. and James L. Butkiewicz. (1995) "The Influence of State-Level Economic Conditions on the 1992 U.S. Presidential Election.” Public Choice, 85, 1-10.

Alvarez, R. Michael and Jonathan Nagler. (1998) "Economics, Entitlements, and Social Issues: Voter Choice in the 1996 Presidential Election." American Journal of Political Science, 42, 1349-1363.

Anselin, Luc. (1988) Spatial Econometrics: Methods and Models. Kluwer Academic Publishers, Dordrecht, NL.

Association of Religion Data Archives (2010). "U.S. Religion Census: Religious Congregations and Membership Study.” Available at www.thearda.com, October.

(C) Southern Regional Science Association 2013. 
Beck, Nathanial, Kristian S. Gleditsch, and Kyle Beardsley. (2006) "Space is More Than Geography: Using Spatial Econometrics in the Study of Political Economy." International Studies Quarterly, 50, 27-44.

Bishop, William. (2004) "The Cost of Political Uniformity," Austin American-Statesman, April 8.

Blackley, Paul R. and Edward M. Shepherd. (1994) "A Statistical Analysis of the Effect of StateLevel Economic Conditions on the 1992 Presidential Election," Public Finance Quarterly, 22, 366-382.

Bureau of Economic Analysis. (2004) Local Area Personal Income and Employment. U.S. Department of Commerce, available at www.bea.gov.

Bureau of Labor Statistics. (2004) Local Area Unemployment Statistics. U.S. Department of Labor, available at www.bls.gov.

Burridge, Peter. (1980) “On the Cliff-Ord Test for Spatial Autocorrelation," Journal of the Royal Statistical Society B, 42, 107-108.

Campbell, James E. (2005) "Why Bush Won the Presidential Election of 2004: Incumbency, Ideology, Terrorism, and Turnout," Political Science Quarterly, 120, 219-241.

Cable News Network (CNN). (2012) Election Results: America Votes 2004. Available at http://www.cnn.com/ELECTION/2004, June.

Census Bureau. (2000) Census 2000 Gateway. U.S. Department of Commerce. Available at http://www.census.gov, May.

Darmofal, David. (2006) "Spatial Econometrics and Political Science," Available at http://polmeth.wustl.edu/media/Paper/DarmofalSpatial.pdf.

Eisenberg, Daniel and Jonathan Ketcham. (2004) "Economic Voting in U.S. Presidential Elections: Who Blames Whom for What," Topics in Economic Analysis \& Policy, 4(1). Article 19.

Elhorst, J. Paul. (2010) “Applied Spatial Econometrics: Raising the Bar," Spatial Economic Analysis, 5, 9-28.

Fair, Ray C. (1996) "Econometrics and Presidential Elections," Journal of Economic Perspectives, 10(3), 89-102.

Florax, Raymond J. G. M., Hendrik Folmer, and Sergio J. Rey. (2003) "Specification Searches in Spatial Econometrics: The Relevance of Hendry's Methodology," Regional Science and Urban Economics, 33, 557-579.

Franzese, Robert J. and Jude C. Hays. (2007a) "Spatial-Econometric Models for Political \& Social Sciences," Available at http://www-personal.umich.edu/franzese/Publications.html.

. (2007b) "Spatial Econometric Models of Cross-Sectional Interdependence in Political Science Panel and Time-Series-Cross-Section Data," Political Analysis, 15, 140-164.

Jones, Jeffrey M. (2004) "The Protestant and Catholic Vote," last accessed at http://www.gallup.com in September 2011.

(C) Southern Regional Science Association 2013. 
Kan, Kamhon and C.C. Yang. (2001) "On Expressive Voting: Evidence from the 1988 U.S. Presidential Election," Public Choice, 108, 295-312.

Kim, Jeongdai, Euel Elliot, and Ding-Ming Wang. (2003) "A Spatial Analysis of Country-Level Outcomes in U.S. Presidential Elections," Electoral Studies, 22, 741-761.

Lacombe, Donald J. and Timothy M. Shaughnessy, T. (2007) "Accounting for Spatial Error Correlation in the 2004 Presidential Popular Vote," Public Finance Review, 35, 480-499.

LeSage, James. (2010) "Econometrics Toolbox," Available at www.spatial-econometrics.com, November.

LeSage, James and R. Kelley Pace. (2008) “A Spatial Hausman Test,” Economics Letters, 101, 282-284. . (2009) Introduction to Spatial Econometrics. CRC Press, New York.

Lewis, Gregory B. (2005) "Same-Sex Marriage and the 2004 Presidential Election," Political Science and Politics, April, 195-199.

McKee, Seth C. and Daron R. Shaw. (2003) "Suburban Voting in Presidential Elections," Presidential Studies Quarterly, 33, 125-144.

Ord, J. Keith (1975) "Estimation Methods for Models of Spatial Interaction," Journal of the American Statistical Association, 70, 120-126.

Sauerzopf, Richard and Todd Swanstrom. (1999) "The Urban Electorate in Presidential Elections, 1920-1996," Urban Affairs Review, 35, 72-91.

Shively, W. Phillips. (1969) “'Ecological' Inference: The Use of Aggregate Data to Study Individuals," American Political Science Association, 63, 1183-1196.

USA Today (2004). "Election 2004," Available at www.usatoday.com, May.

Wines, Michael. (1992) "The 1992 Campaign: White House; Bad Economic News Forces Bush to Refocus Re-Election Strategy,” New York Times, July 4.

(C) Southern Regional Science Association 2013. 